\title{
Impact of different reservoirs on continuity of river water temperature: a temperature trend hypothesis in river
}

\author{
You Xu${ }^{1}$, Zhengjian Yang ${ }^{2}$, Jun $\mathrm{Ma}^{2}$, Yong $\operatorname{Dan}^{3}$, Defu $\mathrm{Liu}^{1}$, and Xiaojuan Guo ${ }^{3}$ \\ ${ }^{1}$ Hubei University of Technology \\ ${ }^{2}$ Hubei Key Laboratory of Ecological Restoration of River-lakes and Algal Utilization \\ ${ }^{3}$ China Three Gorges University
}

May 5, 2020

\begin{abstract}
Water temperature is an important habitat factor in river ecosystems that exhibits the characteristics of continuous change. Dam construction disrupts the continuity of the water temperature and reset it, thus exerting range reduction and hysteresis effects on the characteristics of water temperature change. The effect of a dam on river continuity is directly related to the dam size. To explain this relationship quantitatively, two rivers in China were selected: one river without reservoirs and one river with cascade reservoirs. Through the analysis of the longitudinal change of water temperature in free-flowing rivers, we found that water temperature changes continuously and uniformly in the longitudinal direction. Based on this, a temperature trend hypothesis in river was proposed, and the discontinuity of the water temperature in the reservoir section was evaluated. The result is as follows: (1) In mixed reservoirs, river water temperature remains as continuous as free-flowing rivers. However, the river water temperature has a large discontinuity in the stratified reservoir; (2) Selective withdrawal of stratified reservoirs in January could not remove the discontinuity caused by itself, but it worked in June.
\end{abstract}

\section{Hosted file}

Impact of different reservoirs on continuity of river water temperature a temperature trend hypothesis available at https://authorea.com/users/304455/articles/435145-impact-of-differentreservoirs-on-continuity-of-river-water-temperature-a-temperature-trend-hypothesisin-river

\section{Hosted file}

Figure 1.tif available at https://authorea.com/users/304455/articles/435145-impact-ofdifferent-reservoirs-on-continuity-of-river-water-temperature-a-temperature-trendhypothesis-in-river 
figures/Figure-2/Figure-2-eps-converted-to.pdf 
figures/Figure-3/Figure-3-eps-converted-to.pdf 
figures/Figure-4/Figure-4-eps-converted-to.pdf 
figures/Figure-5/Figure-5-eps-converted-to.pdf 
figures/Figure-6/Figure-6-eps-converted-to.pdf 
figures/Figure-7/Figure-7-eps-converted-to.pdf 


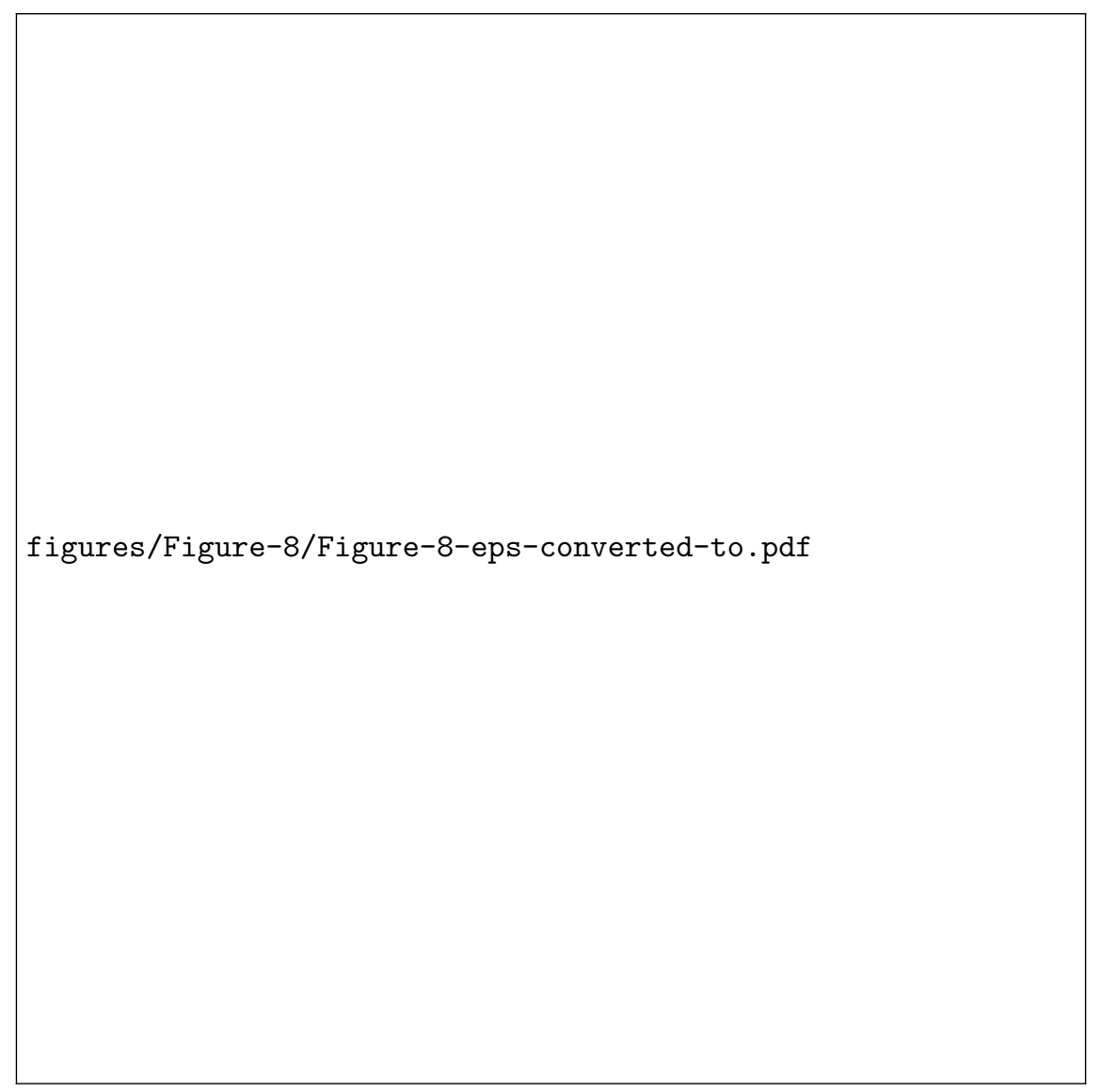

\section{Hosted file}

Table 1.xlsx available at https://authorea.com/users/304455/articles/435145-impact-ofdifferent-reservoirs-on-continuity-of-river-water-temperature-a-temperature-trendhypothesis-in-river

\section{Hosted file}

Table 2.xlsx available at https://authorea.com/users/304455/articles/435145-impact-ofdifferent-reservoirs-on-continuity-of-river-water-temperature-a-temperature-trendhypothesis-in-river

\section{Hosted file}

Table 3.xlsx available at https://authorea.com/users/304455/articles/435145-impact-ofdifferent-reservoirs-on-continuity-of-river-water-temperature-a-temperature-trendhypothesis-in-river

\section{Hosted file}

Table 4.xlsx available at https://authorea.com/users/304455/articles/435145-impact-ofdifferent-reservoirs-on-continuity-of-river-water-temperature-a-temperature-trendhypothesis-in-river 